\title{
Assessment of Drought Tolerance Indices and their Relation with ISSR Markers in Bread Wheat (Triticum aestivum L.)
}

\author{
Behnam FIROOZI', Omid SOFALIAN ${ }^{\prime}$, Majid SHOKRPOUR², \\ Ali RASOULZADEH ${ }^{3}$, Fatemeh AHMADPOOR ${ }^{1}$ \\ ${ }^{1}$ University of Mohaghegh Ardabili, Faculty of Agriculture, Department of Plant Breeding, \\ Ardabil 179,Iran; sofalian@uma.ac.ir (*corresponding author) \\ ${ }^{2}$ University of Tehran, Faculty of Agriculture and Natural Resources, Department of Plant Breeding, Iran \\ ${ }^{3}$ University of Mohaghegh Ardabili, Faculty of Agriculture, Department of Soil Science, Ardabil 179, Iran
}

\begin{abstract}
Water stress is one of the most important environmental abiotic stress that reduced crop yield especially in arid and semi arid regions of the world. In order to identifying drought tolerance, 39 cultivars of spring, facultative and winter type wheat varieties were planted as subplots within the irrigation plots (main plots) in a randomized complete block design with three replications in a research filed of Faculty of Agriculture, University of Mohaghegh Ardabili, Iran. In 2/3 continuous irrigation stress level, based on stress susceptibility, geometric mean productivity and harmonic indices, 'Sepahan,' 'Karaj 3', 'Bahar' and 'Yavaroos' were known as the best varieties; and in $1 / 3$ continuous irrigation stress level, based on the mentioned indices, 'Hirmand,' 'Bahar,', 'Yavaroos' and 'Marvdasht' were the best one. According to biplot resulted from principle coordinate analysis, in 2/3 continuous irrigation 'Moghan 1', 'Golestan', 'Kavir,' 'Maroon', 'Karkheh,' 'Chanaab, '10,' '6, 'Bahar' and 'Sepahan'; and in 1/3 continuous irrigation 'Golestan,' '10', 'Niknejad', 'Maroon', 'Darab', 'Falat', 'Arta,' 'Marvdasht', 'Bahar' and 'Hirmand' were identified as the most tolerant cultivars. According to multiple regression analysis in subject of agronomic traits, 43, 33 and 25 informative ISSR markers identified in control, 2/3 and 1/3 continuous irrigation conditions, respectively. Also among these markers, there were significant relationship between $\mathrm{P}_{12} \mathrm{~L}_{3}$ and $\mathrm{P}_{21} \mathrm{~L}_{3}$ markers with plant height and spike length; $\mathrm{P}_{4} \mathrm{~L}_{1}$ and $\mathrm{P}_{22} \mathrm{~L}_{1}$ markers with flag leaf length; $\mathrm{P}_{19} \mathrm{~L}_{4}$ markers and number of node; $\mathrm{P}_{30} \mathrm{~L}_{4}$ markers and awn length; $\mathrm{P}_{10} \mathrm{~L}_{1}$ and $\mathrm{P}_{22} \mathrm{~L}_{1}$ with peduncle to plant height ratio in all of stress and non-stress conditions.
\end{abstract}

Keywords: drought stress, ISSR molecular markers, multiple regression analysis, principle coordinate analysis, tolerance indices

Abbreviations: TOL-Tolerance Index; Ys-Stress Yield; Yp-Non-stress Yield; MP-Mean of Productivity; SSI-Stress Susceptibility Index; STI-Stress Tolerance Index; GMP-Geometric Mean Productivity; HARM-Harmonic Mean Productivity

\section{Introduction}

Wheat is the most important cereal crops; it is a stable diet for more than one third of the world population and contributes more calories and protein to the world diet than any other cereal crop (Abd-El-Haleem et al., 2009). Drought stress is one of Agriculture fundamental problems in Iran and World; and is important factor in reduction of wheat production (Abdolshahi et al., 2010). Achieving a genetic improvement in yield under these complex circumstances has been recognized to be a difficult challenge for plant breeders (Condon, 2002). According to Fernandez (1992), genotypes can be divided into four groups based on their yield response to stress conditions: (1) genotypes producing high yield under both water stress and non-stress conditions (group A), (2) genotypes with high yield under non-stress (group B) or (3) stress (group C) conditions and (4) genotypes with poor performance under both stress and non-stress conditions (group D). Some researchers believed that selection could be under favorable condition (Betran et al., 2003; Rajaram and Van Ginkel, 2001; Richards, 1996; Van Ginkel et al., 1998). Also selection in the target stress condition has been highly recommended by others (Ceccarelli, 1987; Ceccarelli and Grando, 1991; Rathjen, 1994). Third group of researchers believed that selection must not only be under favorable conditions but also be under stress conditions (Clarke et al., 1992; Fernandez, 1992; Fischer and Maurer, 1978; Rajaram and Van Ginkel, 2001). The suitability of indicators seems to depend on the timing and severity of stress in drought-prone environment. Drought indices which provide a measure of drought based on yield loss under drought conditions in contrast to normal conditions have been used for screening drought-tolerant genotypes (Mitra, 2001). Rosielle and Hamblin (1981) defined stress tolerance (TOL) as the differences in yield between the stress (Ys) and non-stress (Yp) environments and mean productivity (MP) as the average yield of Ys and Yp. Fischer and 
144

Maurer (1978) proposed a stress susceptibility index (SSI) of the cultivar. Fernandez (1992) defined a new advanced index (STI), which can be used to identify genotypes that produce high yield under both stress and non-stress conditions. Other drought stress indices are geometric productivity (GMP), mean productivity (MP), HARM and tolerance (TOL). Many researchers have evaluated these indices. Among the stress tolerance indicators, a larger value of TOL and SSI represent relatively more sensitivity to stress, thus a smaller value of TOL and SSI are favored. Selection based on these two indices favors genotypes with low yield under non-stress conditions and high yield under stress conditions (Golabadi et al., 2006). Sio-Se Mardeh et al. (2006) suggested that selection for drought tolerance in wheat could be conducted for high MP, GMP and STI under stressed and non-stressed environments. Karami et al. (2005) introduce MP, GMP and STI as most proper indices in barley for assessing tolerance to drought.

In recent years, crop physiology and genomics have led to new insights in drought tolerance providing breeders with new knowledge and tools for plant improvement (Tuberosa and Salvi, 2006). Looking for the coincidence of loci for specific traits and loci for yield under drought stress and in stress-free environments, it is possible to test more precisely whether a specific trait is of significance in improving drought tolerance and yield potential. For example in rice, QTLs for plant yield under drought were coincident with QTLs for root traits and OA (Babu et al., 2003). Several major loci for yield under different environmental regimes were mapped along with QTLs for late senescence of the flag leaf in winter wheat (Verma et al., 2004). The inter simple sequence repeats (ISSR) are a new kind of molecular marker involving PCR amplification of DNA by a single primer 16-18 bp long composed of a repeated sequence anchored at the $3^{\prime}$ or $5^{\prime}$ end by $2-4$ arbitrary nucleotides (Zietkiewicz et al., 1994). They are easy to handle, highly informative and repeatable.

The objective of this study was to identify the most suitable indices and cultivars for each both moisture and rain-fed environment.

\section{Materials and methods}

\section{Plant materials}

In this study 39 reputed wheat (T. aestivum) cultivars were used based on their clear differences in yield under irrigated and non-irrigated conditions (Tab. 1). First, the water requirement of wheat was calculated by using of CROPWAT-4 software (Allen et al., 1998). This software calculated the water requirement of wheat and time period of irrigations by using of climatic information gathered from agricultural climatic station of Ardabil province (Iran). Then, $1 / 3$ and $2 / 3$ of total water requirement are chosen for two drought stress levels. Cultivars were planted as subplots within the irrigation plots (main plots) in a randomized complete block design with three replications. Control plots were watered from planting to grain filling stages based on time period of irrigation (calculated by CROPWAT- 4 software). But non-irrigated plots $(1 / 3$ and $2 / 3$ continuous irrigation) received only $1 / 3$ and $2 / 3$ of water requirement. During performance of experiment, no rainfall was occurred. Also, drought tolerance indices were calculated.

\section{DNA Isolation}

Total genomic DNA was extracted from young leaves according to method of Saghai-Maroof et al. (1984). Followed by an RNase-A treatment (Sigma, St. Louis MO; $\mathrm{R}-4875$ ) for $30 \mathrm{~min}$ at $37^{\circ} \mathrm{C}$. Also quantity and quality of samples were tested using spectrophotometry and $0.8 \%$ agarose gel, respectively (CIMMYT, 2005).

\section{ISSR-PCR Reactions}

A total of 34 primers (provided from Bioneer) were tested for ISSR (Tab. 2). Based on the accurate amplified bands profiles and the produced polymorphic patterns of DNA fingerprinting selected 19 different primers. The ISSR amplification reactions were carried out in $20 \mu \mathrm{l}$ per tube, containing $4 \mu \mathrm{l}$ DNA ( $25 \mathrm{ng} / \mu \mathrm{l}), 2 \mu \mathrm{l}$ PCR buffer (10X), $0.8 \mu \mathrm{l} \mathrm{mgcl} 2(50 \mathrm{mM}), 0.2 \mu \mathrm{l} \mathrm{dNTP} \operatorname{mix}(10 \mathrm{mM})$, $1.6 \mu \mathrm{l}$ primer $(5 \mu \mathrm{l}), 0.26$ unit of taq DNA polymerase en-

Tab. 1. The list of cultivars name and their growth type

\begin{tabular}{ccccccccc}
\hline NO. & Cultivar names & Growth type & NO. & Cultivar names & Growth type & NO. & Cultivar names & Growth type \\
\hline 1 & 'Shiroodi' & Spring Wheat & 14 & 'Bahar' & Spring Wheat & 27 & 'Karkheh' & Facultative Wheat \\
\hline 2 & 'Aria' & Spring Wheat & 15 & 'Darab' & Facultative Wheat & 28 & 'Karaj2' & Facultative Wheat \\
3 & 'Darya' & Winter Wheat & 16 & 'Kavir' & Spring Wheat & 29 & 'Roshan' & Facultative Wheat \\
\hline 4 & '10' & Winter Wheat & 17 & 'MS18-14' & Facultative Wheat & 30 & 'Sholeh' & Facultative Wheat \\
5 & 'Kiknejad' & Spring Wheat & 18 & 'Arta' & Facultative Wheat & 31 & 'Arvand' & Spring Wheat \\
6 & 'Atila4' & Spring Wheat & 19 & 'Verinak' & Facultative Wheat & 32 & 'Chanab' & Facultative Wheat \\
7 & 'Akbari' & Spring Wheat & 20 & 'Azadi' & Spring Wheat & 33 & 'Hirmand' & Spring Wheat \\
8 & 'Gods' & Facultative Wheat & 21 & 'Yavaroos' & Spring Wheat & 34 & 'Alborz' & Spring Wheat \\
9 & 'Sepehan' & Winter Wheat & 22 & 'Marvdasht' & Spring Wheat & 35 & 'Falat' & Spring Wheat \\
10 & 'Atila50' & Spring Wheat & 23 & 'Mahdavi' & Facultative Wheat & 36 & 'Maroon' & Facultative Wheat \\
11 & 'Sistan' & Spring Wheat & 24 & 'Chamran' & Spring Wheat & 37 & 'Golestan' & Facultative Wheat \\
12 & 'Moghanl' & Facultative Wheat & 25 & 'Tabasi' & Spring Wheat & 38 & '6 & Winter Wheat \\
13 & 'Karaj3' & Spring Wheat & 26 & 'LineA' & Facultative Wheat & 39 & 'Sorkhtokhm' & Winter Wheat \\
\hline
\end{tabular}


zyme ( 5 unit/ $\mu \mathrm{l}$ ) and $11.14 \mathrm{ddH}_{2} \mathrm{O}$. The following conditions were used for ISSR amplifications:

An initial denaturation step of $94^{\circ} \mathrm{C}$ for $5 \mathrm{~min}$, followed by 40 cycles of denaturation at $94^{\circ} \mathrm{C}$ for $1 \mathrm{~min}$, a primer annealing step at appropriate temperature for 1 min, and an extension at $72^{\circ} \mathrm{C}$ for $1 \mathrm{~min}$; then a final extension was carried out at $72^{\circ} \mathrm{C}$ for $5 \mathrm{~min}$. The annealing temperature varied according to the melting temperature of each primer (Tab. 2). ISSR amplification reactions were carried out on a Gene Amp. PCR system.

\section{Band analysis:}

The reaction products were analyzed by electrophoresis on $1.4 \%$ agarose gel, stained with ethidium bromide, and photographed under UV transilluminator by digital camera with UV filter (Fig. 1). The synthetic DNA, ladder SM 0191 (Fermentas) was employed as a weight markers. Each amplified band profile was defined by the presence (1) or absence of bands (0) at particular positions on the gel. The computer software SPSS ver.16 was used to doing relationship analysis between morphological and molecular data's by method of step by step regression. In addition Minitab ver. 14 was used for drawing biplots.

\section{Results and discussions}

Drought tolerance indices were calculated on the basis of cultivars grain yield. The analysis of variance for indices (Tab. 3) indicates that the differences among cultivars were significant for STI and SSI indices.

SSI index has been widely used by other researchers (Clarke et al., 1984; Fischer and Maurer, 1978; Winter et al., 1988). In this study, SSI appeared to be suitable selection criteria to identify sensitive cultivars from others. In 1/3 continuous irrigation 'Verinak', 'Atila4', 'Atila 50', 'Chanab' were recorded with the highest value of SSI and

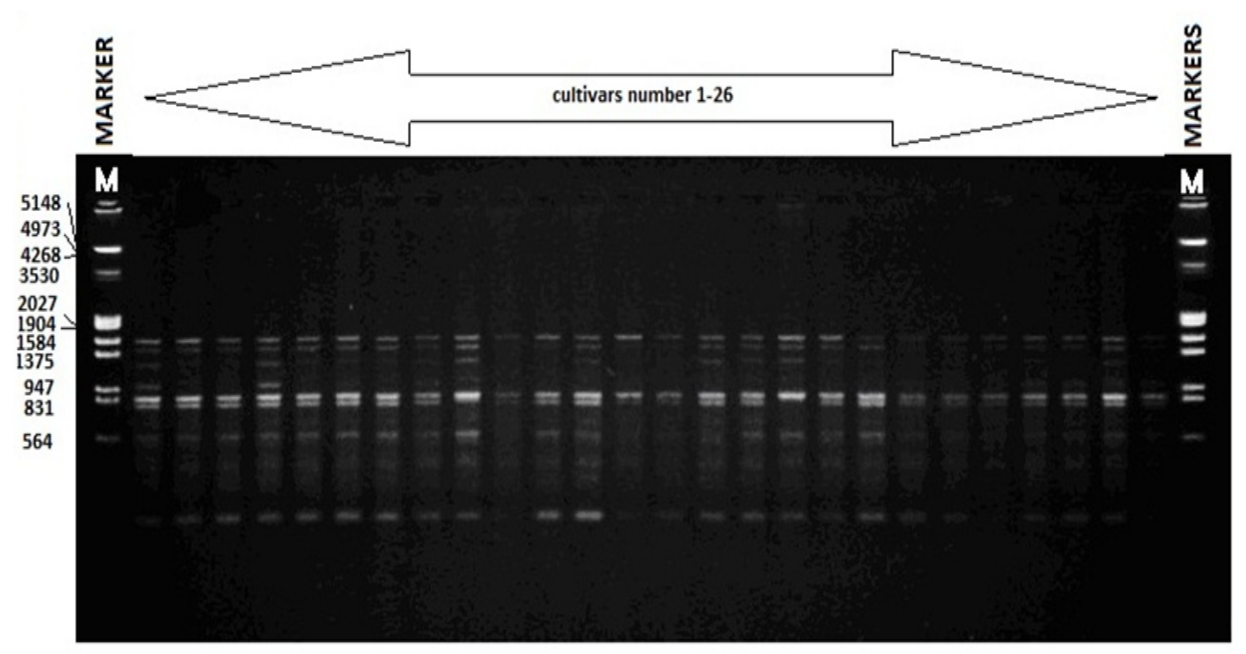

Fig.1. ISSR banding pattern after PCR amplification

Tab. 2. The list of ISSR primers that were used in present study

\begin{tabular}{|c|c|c|c|c|c|}
\hline Primer & Primer Sequence & $\begin{array}{c}\text { Ann. Temp. } \\
\mathrm{C}^{\circ}\end{array}$ & Primer & Primer Sequence & $\begin{array}{c}\text { Ann. Temp. } \\
C^{\circ}\end{array}$ \\
\hline 1 & 5'AGAC AGACGC 3' & 48 & 18 & 5' CСACСACCACCACCA 3' & 50 \\
\hline 2 & 5' GACAGACAGACA GACA 3' & 52 & 19 & 5' AGAGAGAGAGAGAGAGT 3' & 54 \\
\hline 3 & 5’ AGAGAGAGAGAGAGAGC3' & 54 & 20 & 5' AATAATAATDG 3' & 54 \\
\hline 4 & '’ ACAGACAGCG 3' & - & 21 & 5' ACTCACTCGC 3' & 54 \\
\hline 5 & 5' AACAACAACGC 3' & 52 & 22 & 5’ ATGATGATGATGATGATG 3’ & 51 \\
\hline 6 & '5' GATAGATATG 3' & - & 23 & '5' GTGTGTGTGTGTGTGTYG 3' & 54 \\
\hline 7 & 5'GAGAGAGAGAGAGAGAT 3' & 48 & 24 & 5' GACAGACAGACAGACA 3' & 46 \\
\hline 8 & 5' GACGACGACGACG 3' & 56 & 25 & 5' ATCATCATCCG 3' & 51 \\
\hline 9 & 5' ТСТСТСТСТСТСТСТСС 3' & 56 & 26 & 5' GATCGATCGATCGC 3' & 48 \\
\hline 10 & 5' CGTCGTCGTCGT 3' & 46 & 27 & 5' СТТСАСТТСАСТТСА 3' & 48 \\
\hline 11 & 5' GTGGTGGTGGC 3' & 46 & 28 & 5' GAGGAGGAGGC3' & 48 \\
\hline 12 & 5’ TTGTTGTTGTTGTTGC 3’ & 47 & 29 & 5' ACACACACACACACACYT 3 & 48 \\
\hline 13 & 5' ACACACACACACACACYG 3' & 54 & 30 & 5' GAGAGAGAGAGAGAGAC 3' & 48 \\
\hline 14 & 5' CACACACACACAGT 3' & 53 & 31 & 5' CACCACCACGC 3' & 47 \\
\hline 15 & 5'ACGACGACGACGAAC 3' & 52 & 32 & 5'AGAGAGAGAGAGAGAC 3’ & 47 \\
\hline 16 & 5' CACACACACACAAG 3' & 51 & 33 & 5'AAGAAGAAGGC 3' & 46 \\
\hline 17 & 5’ AGAGAGAGAGAGAGAGG 3' & 45 & 34 & 5' CACACACACACACACAG 3' & 47 \\
\hline
\end{tabular}


Tab. 3. Mean square for stress yield and drought tolerance indices

\begin{tabular}{|c|c|c|c|c|c|c|c|c|c|}
\hline \multirow{2}{*}{ S.O.V. } & \multicolumn{9}{|c|}{ Mean square } \\
\hline & d.f. & Ys & d.f. & STI & SSI & d.f. & TOL & HARM & GMP \\
\hline Replication & 2 & $25.97^{\mathrm{ns}}$ & 2 & $0.11^{\mathrm{ns}}$ & $0.16^{\mathrm{ns}}$ & 2 & $18.50^{\mathrm{ns}}$ & $35.15^{\circ}$ & $41.58^{\prime \prime}$ \\
\hline Stress & 1 & $63.68^{\mathrm{ns}}$ & 1 & $3.47^{*}$ & $0.03^{\mathrm{ns}}$ & 1 & $63.68^{\circ}$ & $49.81^{\circ}$ & $33.57^{\circ}$ \\
\hline Replication $\times$ Stress & 2 & 3.33 & - & - & - & 2 & 3.33 & 2.84 & 1.83 \\
\hline Cultivar & 38 & $2.49^{\mathrm{ns}}$ & 38 & $0.25^{*}$ & $0.42^{\circ}$ & 38 & $3.28^{\mathrm{ns}}$ & $2.60^{\mathrm{ns}}$ & $2.37^{\mathrm{ns}}$ \\
\hline Cultivar $\times$ Stress & 38 & $1.07^{\mathrm{ns}}$ & 38 & $0.07^{\mathrm{ns}}$ & $0.24^{\mathrm{ns}}$ & 38 & $1.07^{\circ}$ & $0.94^{*}$ & $0.63^{*}$ \\
\hline Cultivar $\times$ Replication & - & & - & - & - & 76 & $3.40^{\prime \prime}$ & $3.08^{\prime \prime}$ & $2.94^{*}$ \\
\hline Error & 152 & 1.67 & 154 & 0.17 & 0.28 & 76 & 0.61 & 0.48 & 0.31 \\
\hline
\end{tabular}

ns $=$ non-significant $,{ }^{*}=p<0.05,{ }^{* *}=p<0.01$

identified as sensitive cultivars whereas 'Chamran', 'Marvdasht', 'Bahar,' 'Hirmand', with a lower SSI and were resistant.

Drought tolerance indices mean comparison for cultivars showed that, in $2 / 3$ continuous irrigation, based on STI, GMP and HARM indices, 'Sepahan' was known as the best cultivar. This cultivar produce a yield of $5.7 \mathrm{t} / \mathrm{ha}$ in control condition (rank 2) and $4.76 \mathrm{t} / \mathrm{ha}$ in $2 / 3$ continuous irrigation (rank 1). Also, 'Karaj3', 'Bahar' and 'Yavaroos' had a high value of top indices, and produce a favorable yield in both control and stress environment. In this study, the greater the TOL index, the larger the yield reduction under stress environment and the higher the drought sensitivity. The study of TOL index showed the cultivars that had a high yield, but didn't show favorable tolerance to drought stress. For instance, 'Moghan1' and 'Chamran' that had a highest drought stress tolerance (TOL) respectively, but their yields in control and $2 / 3$ continuous irrigation were poor. These cultivars based on SSI index ranked 1 and 2 respectively. At the other hand, 'Sepahan,' 'Karaj3', 'Bahar' and 'Yavaroos' produce a good yield in both conditions; but their TOL and SSI values were not suitable. In $1 / 3$ continuous irrigation, based on STI, GMP and HARM indices, 'Hirmand' identified as the selected cultivar. This cultivar produce 4.51 (rank 4) and 3.6 (rank 1) t/ha grain yield in control and $1 / 3$ continuous irrigation, respectively. Aside from 'Hirmand' cultivar, 'Bahar', 'Yavaroos' and 'Marvdasht' contained high values of top three indices (STI, GMP and HARM). These cultivars produce suitable grain yield in both stress and non-stress conditions too.

The correlation coefficient between grain yield and indices are shown in Tab. 4 and 5 for both $2 / 3$ and $1 / 3$ continuous irrigation stress levels. GMP and STI were significantly correlated with both stress and non-stress yields (Tab. 4). therefore, these indices are able to discriminate group A cultivars from others. The correlation between $Y$ (stress yield) and $Y_{p}$ (non-stress yield) was positive $(+0.578)$ and significant at $1 \%$ level of significance (Tab. 4). Grain yield in stress condition showed significant association with STI, HARM and GMP indices at $1 \%$ and negative relationship with SSI and TOL indices. In non-stress condition, $Y_{p}$ had a positive and significant correlation with all indices except SSI index. A positive association between TOL and $Y_{p}$ and negative correlation between TOL and $\mathrm{Y}_{\mathrm{s}}(\mathrm{Tab} .4)$ in both stress levels suggest that selection based on this index will lead to reduced grain yield under irrigated conditions. This results are similar to Clarke et al. (1992) and Rosielle and Hamblin (1981) studies. SSI was adversely correlated with $Y_{s}$ in two stress levels suggesting that grain yield under stress can contribute to reduce stress susceptibility (Fernandez, 1992).By using of SSI index, Group C and D genotypes are separable from other groups. Stable genotypes based on STI index are containing high values of this index; therefore, it's expect group A genotypes are separable from others by use of this index. Narayan and Misra (1989) found that, SSI index has a significant and positive $(+0.71)$ correlation with yield in non-stress condition. Selection based on MP index, generally lead to yield improvement in both stress and non-stress environment, but not able to separate group $\mathrm{A}$ from $\mathrm{B}$ one (Fernandez, 1992). The highest correlation coefficient between yield in control condition, result from GMP, STI and HARM indices respectively. But in $2 / 3$ continuous irrigation the highest association was between $Y_{p}$ with HARM, GMP and STI indices respectively. According to Tab. 4. Correlation coefficient between yield in $2 / 3$ continuous irrigation stress level and drought tolerance indices

\begin{tabular}{|c|c|c|c|c|c|c|c|}
\hline & $Y p$ & Ys & TOL & STI & SSI & HARM & GMP \\
\hline$Y p$ & 1 & & & & & & \\
\hline Ys & $0.578^{* *}$ & 1 & & & & & \\
\hline TOL & $0.419^{* *}$ & $-0.498^{* *}$ & 1 & & & & \\
\hline STI & $0.813^{* *}$ & $0.931^{* *}$ & -0.172 & 1 & & & \\
\hline SSI & 0.039 & $-0.773^{* *}$ & $0.902^{* *}$ & $-0.498^{* *}$ & 1 & & \\
\hline HARM & $0.765^{* *}$ & $0.966^{* *}$ & -0.261 & $0.983^{* *}$ & $-0.595^{* *}$ & 1 & \\
\hline GMP & $0.824^{* *}$ & $0.938^{* *}$ & -0.169 & $0.988^{* *}$ & $-0.520^{* *}$ & $0.995^{* *}$ & 1 \\
\hline
\end{tabular}

ns $=$ non-significant, ${ }^{*}=p<0.05,{ }^{* *}=p<0.01$ 
Tab. 5. Correlation coefficient between yield in 1/3 continuous irrigation stress level and drought tolerance indices

\begin{tabular}{|c|c|c|c|c|c|c|c|}
\hline & $Y p$ & Ys & TOL & STI & SSI & HARM & GMP \\
\hline$Y p$ & 1 & & & & & & \\
\hline Ys & $0.516^{* *}$ & 1 & & & & & \\
\hline TOL & $0.494^{* *}$ & $-0.490^{* *}$ & 1 & & & & \\
\hline STI & $0.729^{* *}$ & $0.955^{* *}$ & -0.227 & 1 & & & \\
\hline SSI & -0.037 & $-0.860^{* *}$ & $0.835^{* *}$ & $-0.677^{* *}$ & 1 & & \\
\hline HARM & $0.632^{* *}$ & $0.983^{* *}$ & $-0.355^{*}$ & $0.972^{* *}$ & $-0.785^{* *}$ & 1 & \\
\hline GMP & $0.731^{* *}$ & $0.955^{* *}$ & -0.266 & $0.983^{* *}$ & $-0.698^{* *}$ & $0.991^{* *}$ & 1 \\
\hline
\end{tabular}

ns $=$ non-significant, ${ }^{*}=p<0.05,{ }^{* *}=p<0.01$

Fernandez (1992), the index that contained high and significant correlation with $Y$ and $Y$, in which based on kind of association lead to yield improvement in both stress and non-stress environments, are introduced as the best index. The results of correlation between grain yield and indices in $1 / 3$ continuous irrigation were very similar to $2 / 3$ continuous irrigation (Tab. 5). In this stress level, the relationship between $Y$ with Y, STI, HARM and GMP were positive and significant. $Y_{s}$ and SSI, TOL indices showed negative and significant association. In general, comparison among GMP, STI and HARM it was showed that the selection on the basis of these criteria resulted cultivars with high yield in both stress and non-stress conditions, because these indices had a positive and significant correlation with grain yield at $1 \%$ in both conditions. Other researchers have reported the same characteristics for those indices (Ahmadi, 2009; Fernandez, 1992; Noormandmoayyed 2007; Rosiell Hamblin, 1981; Shafazadeh et al., 2004). Some researchers attempted to determine the best criteria in order to selection desired genotypes for dry lands. For example, Ehdaie et al. (1988) reported that the relationship among SSI with grain yield and harvest index (HI) were -0.84 and -0.83 , respectively. Also, SSI index and grain yield didn't show significant association in nonstress condition. Ahmadi and Siose Mardeh (2003) found that among studied indices, STI and MP are effective in separating group A cultivars from others. It's appeared the highest and lowest value of MP and STI indices showed group $\mathrm{A}$ and $\mathrm{B}$ genotypes, respectively.

When breeding for drought resistance is the aim, two situations seem to be clearly distinguished in order to choose a selection strategy: (1) where the drought condition is predominant over the years are infrequent, and (2) where the drought condition happens rarely and wet wears are predominant (Sio-se Mardeh et al., 2006). In the regions with the former situation (such as many parts of Iran), selection should be based on the yield in the target environment (Ceccarelli, 1987; Ceccarelli and Grando, 1991; Rathjen, 1994). Where the latter situation exists, selection in favorable environment will be more effective (Betran et al., 2003; Rajaram and Van Ginkel, 2001; Richards, 1996; Van Ginkel et al., 1998).

Because of performance of GMP and STI indices in identifying Group A genotypes, and high correlation among GMP and STI, 3D plot of STI index are shown in Fig. 2 for $2 / 3$ and $1 / 3$ continuous irrigation. Based on this plot, in $2 / 3$ continuous irrigation 'Line A', 'Sepahan', 'Yavaroos', 'Bahar', 'Hirmand', 'Akbari', 'Roshan', 'MS 1814 ' and 'Arta'; and in $1 / 3$ continuous irrigation 'Line A', 'Bahar,' 'Hirmand,' 'Yavaroos,' 'Marvdasht', 'Arta' and 'Sep-

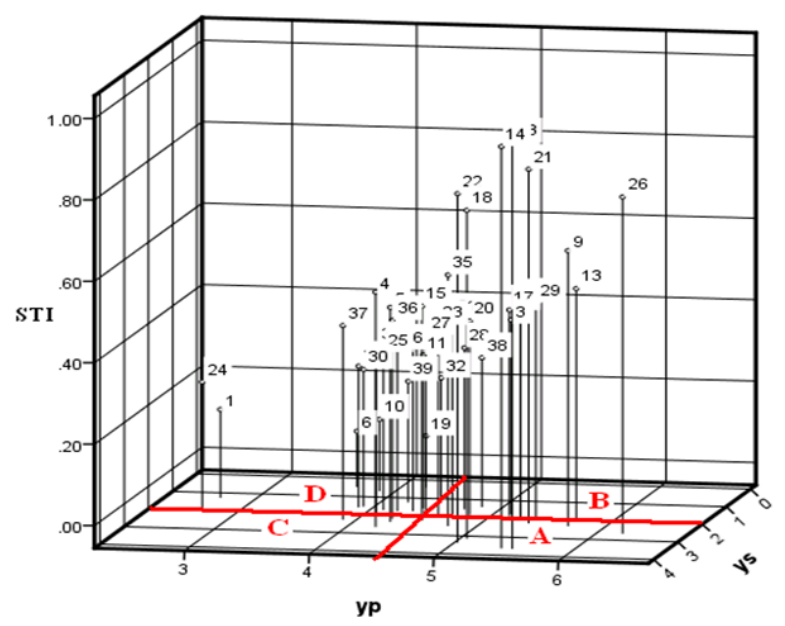

Fig. 2. 3D plot of cultivars based on STI index. A (2/3 continuous irrigation), B (1/3 continuous irrigation)

1-'Shiroodi'; 2-'Aria'; 3-'Darya'; 4-'10'; 5-'Kiknejad'; 6-'Atila4'; 7-'Akbari'; 8-'Gods'; 9-'Sepehan'; 10-'Atila50'; 11-'Sistan'; 12-'Moghanl'; 13-'Karaj3'; 14-'Bahar'; 15-'Darab'; 16-'Kavir'; 17-'MS 18-14'; 18-'Arta'; 19-'Verinak'; 20-'Azadi'; 21-'Yavaroos'; 22-'Marvdasht'; 23-'Mahdavi' 24-'Chamran'; 25-'Tabasi'; 26-'LineA'; 27-'Karkheh'; 28-'Karaj2'; 29-'Roshan'; 30-'Sholeh'; 31-'Arvand'; 32-'Chanab'; 33-'Hirmand'; 34-Alborz'; 35-'Falat'; 36-'Maroon'; 37-'Golestan'; 38-'6'; 39-'Sorkhtokhm' 
148

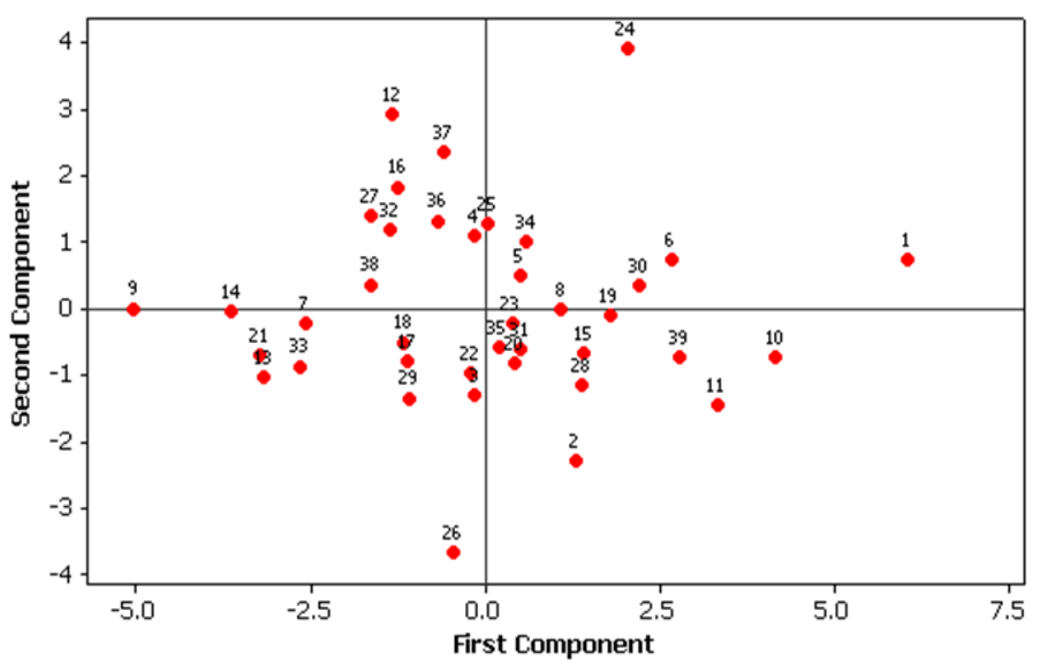

Fig. 3. Cultivars distribution biplot based on two first component for $2 / 3$ continuous irrigation

1-'Shiroodi'; 2-Aria'; 3-'Darya'; 4-'10'; 5-'Kiknejad'; 6-'Atila4'; 7-'Akbari'; 8-'Gods'; 9-'Sepehan'; 10-'Atila50'; 11-'Sistan'; 12-'Moghan1'; 13-'Karaj3'; 14-'Bahar'; 15-'Darab'; 16-'Kavir'; 17-'MS 18-14'; 18-'Arta'; 19-'Verinak'; 20-'Azadi'; 21-'Yavaroos'; 22-'Marvdasht'; 23-'Mahdavi' 24-'Chamran'; 25-'Tabasi'; 26-'LineA'; 27-'Karkheh'; 28-'Karaj2'; 29-'Roshan'; 30-'Sholeh'; 31-'Arvand'; 32-'Chanab'; 33-'Hirmand'; 34-Alborz'; 35-'Falat'; 36-'Maroon'; 37-'Golestan'; 38-'6';

39-'Sorkhtokhm'

ahan' are divided into group A (Fig. 2). These cultivars had a high value of STI and GMP; and this showed advantage of these two indices in separating group A genotypes from others. Thus, better approach than a correlation analysis to identifying the superior cultivars for both stress and non-stress environments is PCA analysis. According to principle coordinate analysis, in $2 / 3$ continuous irrigation, $70.5 \%$ of the variation between $Y_{p}, Y$, TOL, STI, GMP, HARM and SSI explained by the first component and $28.7 \%$ by the second one. Similar to $2 / 3$ continuous irrigation, in $1 / 3$ continuous irrigation, the first component explained $72.5 \%$ of the total variability and correlated negatively with $Y_{p}, Y_{s}, S T I, H A R M$ and GMP indices. 26.7 percent of variation among $Y_{p}, Y_{s}$ and indices explained by second component that negatively correlated with $Y_{p}$, TOL, SSI, STI, HARM and GMP indices. Based on these components, cultivars distribution biplot were drawn by using of Minitab14 software (Fig. 3 for $2 / 3$ continuous irrigation and Fig. 4 for $1 / 3$ continuous irrigation). In these plots, cultivars were grouped in four zones. Since the high value of the second component and the low value of the first component are favorable, so the top-left corner of the plot contain the cultivars that produce high yield and also tolerant to drought stress. These cultivars are 'Moghan 1',

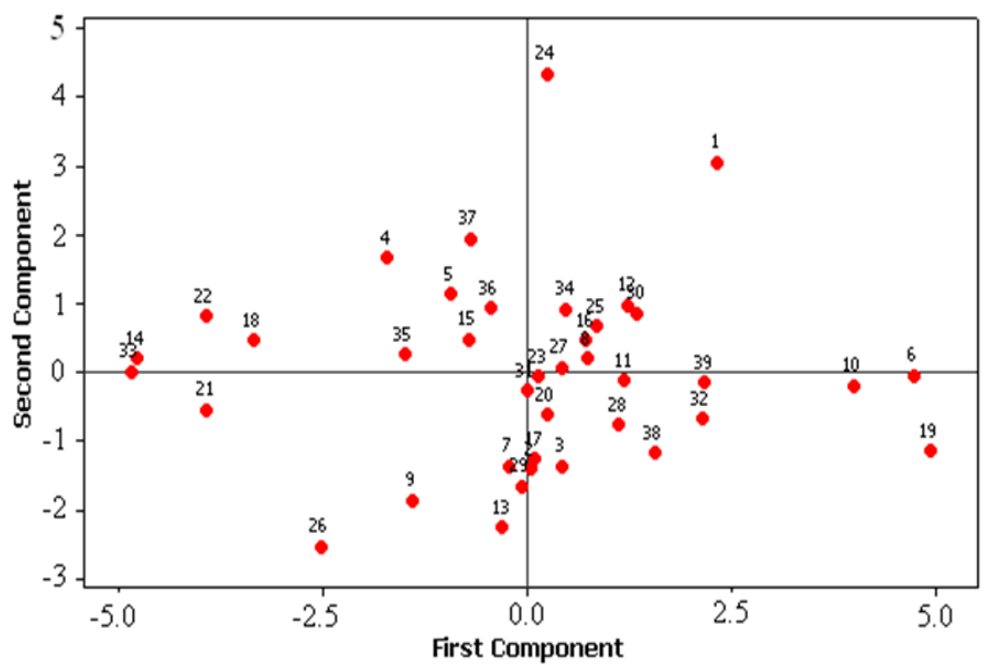

Fig. 4. Cultivars distribution biplot based on two first component for $1 / 3$ continuous irrigation

1-'Shiroodi'; 2-'Aria’; 3-'Darya'; 4-'10'; 5-'Kiknejad'; 6-'Atila44; 7-'Akbari'; 8-'Gods'; 9-'Sepehan'; 10-'Atila50'; 11-'Sistan'; 12-'Moghan1'; 13-'Karaj3'; 14-'Bahar'; 15-'Darab'; 16-'Kavir'; 17-'MS 18-14; 18-'Arta'; 19-'Verinak'; 20-'Azadi'; 21-'Yavaroos'; 22-'Marvdasht'; 23-'Mahdavi' 24-'Chamran'; 25-'Tabasi'; 26-'LineA'; 27-'Karkheh'; 28-'Karaj2'; 29-'Roshan'; 30-'Sholeh'; 31-'Arvand'; 32-'Chanab'; 33-'Hirmand'; 34-Alborz'; 35-'Falat'; 36-'Maroon'; 37-'Golestan'; 38-'6'; 39-'Sorkhtokhm' 
Tab. 6. Regression coefficients between markers and drought tolerance indices in $2 / 3$ continuous irrigation

\begin{tabular}{cccccc}
\hline Marker & TOL & STI & SSI & HARM & GMP \\
\hline Constant & 0.446 & 0.574 & -0.22 & 2.191 & 2.803 \\
$\mathrm{P}_{4} \mathrm{~L}_{6}$ & & $-0.446^{* *}$ & & $-0.451^{* *}$ & $-0.467^{* *}$ \\
$\mathrm{P}_{5} \mathrm{~L}_{1}$ & & & & & \\
$\mathrm{P}_{5} \mathrm{~L}_{3}$ & & $0.622^{* *}$ & & $0.667^{* *}$ & $0.685^{* *}$ \\
$\mathrm{P}_{11} \mathrm{~L}_{3}$ & & $0.336^{*}$ & & $0.319^{*}$ & $0.336^{*}$ \\
$\mathrm{P}_{30} \mathrm{~L}_{4}$ & $-0.348^{*}$ & & $-0.421^{* *}$ & & \\
$\mathrm{P}_{30} \mathrm{~L}_{5}$ & & & & & \\
$\mathrm{P}_{30} \mathrm{~L}_{6}$ & & & $-0.349^{*}$ & & \\
$\begin{array}{l}\text { Adjusted } \\
\text { R square }\end{array}$ & 0.313 & 0.338 & 0.17 & 0.497 & 0.416 \\
\hline${ }^{*}=p<0.05,{ }^{* *}=p<0.01$ & & & &
\end{tabular}

Tab. 7. Regression coefficients between markers and drought tolerance indices in $1 / 3$ continuous irrigation

\begin{tabular}{cccccc}
\hline Marker & TOL & STI & SSI & HARM & GMP \\
\hline Constant & 3.316 & 0.478 & 1.583 & 2.779 & 3.053 \\
$\mathrm{P}_{2} \mathrm{~L}_{1}$ & & $-0.684^{* *}$ & & $-0.626^{* *}$ & $-0.453^{* *}$ \\
$\mathrm{P}_{4} \mathrm{~L}_{6}$ & & & & & \\
$\mathrm{P}_{5} \mathrm{~L}_{1}$ & & & & $0.362^{* *}$ & $0.425^{* *}$ \\
$\mathrm{P}_{19} \mathrm{~L}_{3}$ & & $0.402^{* *}$ & & $0.323^{*}$ & \\
$\mathrm{P}_{21} \mathrm{~L}_{1}$ & $0.317^{*}$ & & $0.332^{*}$ & & \\
$\mathrm{P}_{21} \mathrm{~L}_{2}$ & $-0.366^{* *}$ & & & & \\
$\mathrm{P}_{22} \mathrm{~L}_{1}$ & & & & $0.452^{* *}$ & $0.522^{* *}$ \\
$\mathrm{P}_{30} \mathrm{~L}_{4}$ & & $0.318^{*}$ & & $0.315^{*}$ & \\
$\mathrm{P}_{30} \mathrm{~L}_{5}$ & $0.326^{*}$ & & $0.340^{*}$ & & \\
$\begin{array}{c}\text { Adjusted } \mathrm{R} \\
\text { square }\end{array}$ & 0.097 & 0.274 & 0.225 & 0.307 & 0.332 \\
\hline${ }^{*}=p<0.05,{ }^{* *}=p<0.01$ & & & & & \\
\hline
\end{tabular}

'Golestan', 'Kavir', 'Maroon', 'Karkheh', 'Chanab', '10', ‘6', 'Bahar' and 'Sepahan' for 2/3 continuous irrigation (Fig. 3); and 'Golestan,' '10,' 'Niknejad,' 'Maroon,' 'Darab,' 'Falat', 'Arta, 'Marvdasht,' 'Bahar' and 'Hirmand' for $1 / 3$ continuous irrigation (Fig. 4). Also the reverse corner (the bottomright corner of the plot) including cultivars that produce low yield and are sensitive to drought stress.

In order to establishment of association between a molecular markers and a part of the quantitative variation of 34 ISSR primers were evaluated. It was applied step by step regression for identification the relationship between ISSR markers and agronomic traits and it was revealed significant differences between alleles in quantitative indices. In the basis of regression analysis results, 43 positive primers were detected for agronomic traits. The number of markers linked to a traits differed from 2 (grain yield) to 10 (awn length) in control condition, zero (number of floret and grain weight/ear) to 11 (number of infertile spike and plant height) in $2 / 3$ continuous irrigation, and zero (number of spike/ear and 1000 grain weight) to 7 (awn length) in $1 / 3$ continuous irrigation stress level. In the control condition, the maximum number of significant association between molecular markers belonged to $\mathrm{P}_{2} \mathrm{~L}_{1}$, $\mathrm{P}_{12} \mathrm{~L}_{3}$, and $\mathrm{P}_{22} \mathrm{~L}_{1}$ markers. In $2 / 3$ and $1 / 3$ continuous irri- gation stress levels, 33 and 25 positive markers were found, respectively. In $2 / 3$ continuous irrigation stress level, $\mathrm{P}_{2} \mathrm{~L}_{1}$, $\mathrm{P}_{21} \mathrm{~L}_{3}$ and $\mathrm{P}_{30} \mathrm{~L}_{4}$ were maximum number of significant relationship with agronomic traits. Also in $1 / 3$ continuous irrigation stress level, the $\mathrm{R}^{2}$ was more than $50 \%$ for spike length, flag leaf length and awn length. Finally, between these molecular markers, following markers had a significant relationship in all three stress levels, jointly: $\mathrm{P}_{12} \mathrm{~L}_{3}$ and $\mathrm{P}_{21} \mathrm{~L}_{3}$ markers with plant height and spike length, $\mathrm{P}_{4} \mathrm{~L}_{1}$ and $\mathrm{P}_{22}^{21} \mathrm{~L}_{1}$ with flag leaf length, $\mathrm{P}_{19} \mathrm{~L}_{4}$ with number of node, $\mathrm{P}_{30}^{22} \mathrm{~L}_{4}$ with awn length, $\mathrm{P}_{10} \mathrm{~L}_{1}$ and $\mathrm{P}_{22} \mathrm{~L}_{1}$ with peduncle to plant height ratio. In addition, analysis of linear regression (method of stepwise) revealed that in $2 / 3$ continuous irrigation stress level, 7 markers had a significant relationship with drought tolerance indices in $1 \%$ or $5 \%$ significance levels (Tab. 6 and 7). $\mathrm{P}_{4} \mathrm{~L}_{6}, \mathrm{P}_{5} \mathrm{~L}_{3}$ and $\mathrm{P}_{11} \mathrm{~L}_{3}$ markers were associated with STI, HARM and GMP, jointly (Tab. 6). Taking notice of correlation among STI, HARM and GMP (Tab. 4), these results suggest that $\mathrm{P}_{4} \mathrm{~L}_{6}, \mathrm{P}_{5} \mathrm{~L}_{3}$ and $\mathrm{P}_{11} \mathrm{~L}_{3}$ markers are part of QTL's or linked to them, probably. In $1 / 3$ continuous irrigation stress level, 9 markers are detected (Tab. 7). $\mathrm{P}_{2} \mathrm{~L}_{1}$ (negatively), $\mathrm{P}_{19} \mathrm{~L}_{3}$ and $\mathrm{P}_{30} \mathrm{~L}_{4}$ (positively) are related to HARM and STI indices (Tab. 7). The correlation between Yp and Ys are positively significant (Tab. 5). The relationship among $\mathrm{P}_{2} \mathrm{~L}_{1}$ and $\mathrm{P}_{30} \mathrm{~L}_{5}$ with TOL and SSI indices is significant (Tab. 4). The TOL and SSI are positively associated together. Based on mentioned results in $1 / 3$ continuous irrigation, it could be declared, probably, grain yield (formed drought tolerance indices) or 3 markers related to HARM and GMP $\left(P_{2} L_{1}, P_{5} L_{1}\right.$ and $\left.\mathrm{P}_{22} \mathrm{~L}_{1}\right)$ e.g., linked to QTL's or are part of them.

\section{Conclusions}

This study showed that molecular markers are important and fast tools to assessing genetic diversity in cultivars. ISSR markers by way of their extension, each utilization and content of information have a high importance in agricultural researches. Nevertheless, indispensably suggest that in breeding programs, other data such as morpho and physiological findings were also used besides of these results.

\section{Acknowledgment}

The authors had especially thanks to seed and Plant Institute of Research (Iran) for preparing the cultivars.

\section{References}

Abd-El-Haleem SHM, Reham MA, Mohamed MS (2009). Genetic analysis and RAPD polymorphism in some durum wheat genotypes. Global J Biotech Biochem 4(1):1-9.

Abdolshahi R, Omidi M, Talei AR, Yazdi Samadi B (2010). Evaluation of bread wheat genotypes for drought tolerance. Elec J Crop Prod 3(1):159-171 (In Persian).

Ahmadi A, Siosemardeh A (2003). Relationships among growth 
150 indices, drought resistance and yield in wheat cultivars of different climates of Iran under stress and non-stress conditions. Iranian J Agric Sci 34(3):667-667 (In Persian).

Ahmadi J (2009). Study of drought resistance in commercially Late-maturing dent corn hybrids. MSc. Diss. University of Tehran (In Persian).

Allen RG, Pereira LS, Raes D, Smith M (1998). Crop evapotranspiration, Guidelines for computing crop water requirements. FAO irrigation and drainage, $300 \mathrm{p}$.

Babu CR, Nguyen BD, Chamarerk V, Shanmugasundaram P, Chezhian P, Juyaprakash P, Ganesh SK, Palchamy A, Sadasivam S, Sarkarung S, Wade LJ, Nguyen TH (2003). Genetic analysis of drought resistance in rice by molecular markers: association between secondary traits and field performance. Crop Sci 43:1457-1469.

Betran FJ, Beck D, Banziger M, Edmeades GO (2003). Genetic analysis of inbred and hybrid grain yield under stress and nonstress environments in tropical maize. Crop Sci 43:807817.

Ceccarelli S (1987). Yield potential and drought tolerance of segregating populations of barely in contrasting environments. Euphytica 40:197-205.

Ceccarelli, S, Grando S (1991). Selection environment and environmental sensitivity in barely. Euphytica 57:157-167.

CIMMYT (2005). Laboratory Protocols: CIMMYT Applied Molecular Genetics Laboratory. Third Edition. Mexico, D.F.: CIMMYT.

Clarke JM, De Pauw RM, Townley-Smith TM (1992). Evaluation of methods for quantification of drought tolerance in wheat. Crop Sci 32:728-732.

Clarke JM, Towenley-Smith TM, McCaig TN, Green DG (1984). Growth analysis of spring wheat cultivars of varying drought resistance. Crop Sci 24:537-541.

Condon AF (2002). Breeding opportunities for increasing the efficiency of water use and crop yield in temperate cereals. Crop Sci 42:111-121.

Ehdaie B, Waines JW, Hall AE (1988). Differential response of landrace and improved spring wheat genotypes to stress environments. Crop Sci 28:838-842.

Fernandez GCJ (1992). Effective selection criteria for assessing stress tolerance. In: Kuo CG (Ed.). Proc of the Internat Sympo on Adaptation of Vegetables and Other Food Crops in Temperature and Water Stress, Publication, Tainan, Taiwan.

Fischer RA, Maurer R (1978). Drought resistance in spring wheat cultivars. Part 1: grain yield response. Aust J Agric Res 29:897-912.

Golabadi M, Arzani A, Maibody SAM. (2006). Assessment of drought tolerance in segregating populations in durum wheat. Afr J Agric Res 5:162-171.

Karami E, Ghannadha MR, Naghavi MR, Mardi M (2005). Identifying of drought tolerant varieties in barley. Iranian J Agri Sci 37:371-379 (In Persian).

Mitra J (2001). Genetics and genetic improvement of drought resistance in crop plants. Curr Sci 80:758-762.

Narayan D, Misra RD (1989). Drought resistance in varieties of wheat in relation to root growth and drought indices. Indonesian J of Agri Sci 59(9):595-598.

Noormand-Moayyed F (2007). Evaluation of quantitative traits and their relationship with bread wheat yield in rain-fed and watered conditions and identifying the best drought resistance index. M. Sc. Of plant breeding thesis. Faculty of agriculture. University of Tehran, 127 p. (In Persian).

Rajaram S, Van Ginkel M (2001). Mexico, 50 years of international wheat breeding, 579-604 p. In: Bonjean AP, Angus WJ (Eds.). The world Wheat Book. A History of Wheat Breeding, . Paris, France. Lavoisier Publishing.

Rathjen AJ (1994). The biological basis of genotype $\times$ environment interaction: Its definition and management. In: Proc of the Seventh Assembly of the Wheat Breeding Society of Australia.

Richards RA (1996). Defining selection criteria to improve yield under drought. Plant Growth Regul 20:157-166.

Rosielle AA, Hamblin J (1981). Theoretical aspects of selection for yield in stress and non-stress environment. Crop Sci 21:943-946.

Saghai-Maroof MA, Soliman KM, Jorgensen RA, Allard RW (1984). Ribosomal DNA spacer length polymorphism in barley: Mendelian inheritance, chromosome location and population dynamics. Proc Nat Acad Sci USA 89:14771481.

Shafazadeh MK, Yazdansepas A, Amini A, Ghannadha MR (2004). Study of terminal drought tolerance in promising winter and facultative wheat genotypes using stress susceptibility and tolerance indices. Sapling and Seed 20(1):57-71 (In Persian).

Sio-Se Mardeh A, Ahmadi A, Poustini K, Mohammadi V (2006). Evaluation of drought resistance indices under various environmental conditions. Field Crop Res 98:222-229.

Tuberosa R, Salvi S (2006). Genomics-based approaches to improve drought tolerance of crops. Trends Plant Sci 11:405412.

Van Ginkel M, Calhoun DS, Gebeyehu G, Miranda A, Tianyou C, Pargas Lara R, Trethowan RM, Sayre K, Crossa J, Rajaram S (1998). Plant traits related to yield of wheat in early, late, or continuous drought conditions. Euphytica 100:109-121.

Verma V, Foulkes MJ, Worland AJ, Sylvester-Bradley R, Caligari PDS, Snape JW (2004). Mapping quantitative trait loci for flag leaf senescence as a yield determinant in winter wheat under optimal and drought-stressed environments. Euphytica 135:255-263.

Winter SR, Musick JT, Porter KB (1988). Evaluation of screening techniques for breeding drought-resistance winter wheat. Crop Sci 28:512-516.

Zietkiewicz E, Rafalski A, Labuda D (1994). Genome fingerprinting by simple sequence repeats (SSR)-anchored polymerase chain reaction amplification. Genomics 20:176183. 